\title{
Alphabetisches Verzeichnis
}

Seite

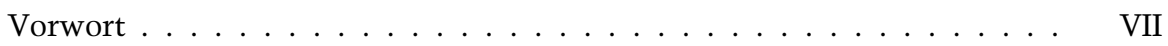

Systematisches Verzeichnis. . . . . . . . . . . . . . X XI

Literaturverzeichnis . . . . . . . . . . . . . . . XXXXX

Rz. Seite
A

Allgemeine Geschäftsbedingungen .............. A 1 A 1

Ambulanz........................... A 8018

Anfängereingriffe, Anfängeroperationen. . . . . . . . A A 10022

Anscheinsbeweis........................ A 16038

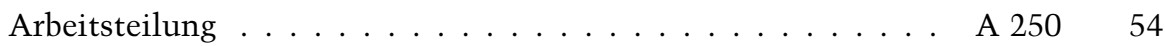

Arztvertrag ................................ 401103

Aufklärung . . . . . . . . . . . . . . . . . A A 501129

Befundsicherungspflicht. . . . . . . . . . . . . . B 1557

Behandlungsfehler . . . . . . . . . . . . . . . . . B B 20560

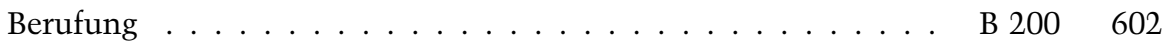

Beweislastumkehr, Beweisvereitelung ........... B 471683

Beweisverfahren, selbständiges . . . . . . . . . . . . . B 500697

Diagnosefehler .......................... D 1722

Dokumentationspflicht . . . . . . . . . . . . . D 201792

Einsicht in Krankenunterlagen . . . . . . . . . . . . . . E E 1848

Einzelrichter ..................... E 50857

Feststellungsinteresse . . . . . . . . . . . . . . . F F 1895

Früherkennung, fehlerhafte pränatale Diagnostik . . . . . . . F 41866 


\section{Alphabetisches Verzeichnis}

Gemeinschaftspraxis .................... G 1878

Genetische Beratung. . . . . . . . . . . . . . G G6 895

Grobe Behandlungsfehler . . . . . . . . . . . . . . . . . . . . G 101903

Kausalität . . . . . . . . . . . . . . . . . . . K K 11133

Klage $($ Muster $\ldots \ldots \ldots \ldots \ldots$ K . . . . . . . . . . . . . 801147

Klageerwiderung (Muster) . . . . . . . . . . . . . . . . . . . . . K 1101169

Krankenhausverträge . . . . . . . . . . . . . . . . . . K 1301178

Mitverschulden des Patienten . . . . . . . . . . . M 11205

Nichterkennen einer Schwangerschaft . . . . . . . . . . . N N 11214

Patientenrechtegesetz ................... P P 1212

Rückerstattung des Honorars . . . . . . . . . . . . . . . . R 11243

Sachverständigenbeweis. . . . . . . . . . . . . . S S 11260

Schwangerschaftsabbruch, fehlerhafter ........... S S 2001321

Sterilisation, fehlerhafte. . . . . . . . . . . . . . . S 3001341

Sturz im Pflegeheim und im Krankenhaus . . . . . . . . . . . S S 5001352

Substantiierung der Klage/Schlüssigkeit f . . . . . . . . . . . . S S600 1376

Suizidgefährdete Patienten . . . . . . . . . . . . . . . . . . . S S 6301383

Therapiefehler ......................... T 1 . 1389

Unterlassene Befunderhebung . . . . . . . . . . . . . . U U 11452

Verjährung ........................... V 11568

Voll beherrschbare Risiken . . . . . . . . . . . . . . . . . V 3011611

Stichwortverzeichnis . . . . . . . . . . . . . . . . . 1645 